Classification

Physics Abstracts

$0.678-6.150$

\title{
MOBILITIES OF POSITIVE IONS IN SOME GAS MIXTURES USED IN PROPORTIONAL AND DRIFT CHAMBERS
}

\author{
G. SCHULTZ \\ Centre de Recherches Nucléaires (Laboratoire PNPP-HE) Strasbourg, France \\ and Ecole d'Ingénieurs Physiciens, Strasbourg, France \\ G. CHARPAK and F. SAULI \\ CERN, Geneva, Switzerland
}

(Reçu le 11 décembre 1975, révisé le 11 juin 1976, accepté le 2 septembre 1976)

\begin{abstract}
Résumé. - Le coefficient de mobilité des ions positifs a été mesuré pour plusieurs mélanges gazeux couramment utilisés dans les chambres proportionnelles et les chambres à migration, à savoir Ar- $\left(\mathrm{OCH}_{3}\right)_{2} \mathrm{CH}_{2}, \mathrm{Ar}-\left(\mathrm{OCH}_{3}\right)_{2}-\mathrm{IsoC}_{4} \mathrm{H}_{10}, \mathrm{Ar}-\mathrm{CH}_{4}$, et $\mathrm{Ar}-\mathrm{CO}_{2}$. La loi de Blanc est vérifiée pour tous les mélanges gazeux étudiés, sauf dans le cas des mélanges argon-isobutane-méthylal à faible proportion de méthylal. Cette loi permet de calculer la mobilité des ions positifs dans n'importe quel mélange gazeux étudié et quelle que soit la proportion des divers constituants du mélange.
\end{abstract}

Abstract. - We have measured the mobility of positive ions in several gas mixtures frequently used in proportional and drift chambers, namely $\mathrm{Ar}-\left(\mathrm{OCH}_{3}\right)_{2} \mathrm{CH}_{2}, \mathrm{Ar}-\left(\mathrm{OCH}_{3}\right)_{2} \mathrm{CH}_{2}-\mathrm{IsoC}_{4} \mathrm{H}_{10}$, $\mathrm{Ar}-\mathrm{CH}_{4}$, and $\mathrm{Ar}-\mathrm{CO}_{2}$. In all gas mixtures considered, Blanc's law of positive ion mobility has been verified, except for a very small methylal concentration in argon-isobutane-methylal. The law permits the calculation of ion mobility in any mixture of the gases considered.

1. Introduction. - In the process of gas amplification around the anode wires in proportional or drift chambers, electron multiplication gives rise to the production of positive ions. Apart from the fact that these ions themselves play a part in producing the electrical pulse collected on the anode wire [1], there are two reasons why, it is important to have information on the nature of the ions which migrate towards the cathode and their mobility.

i) Many physicists have operated proportional chambers or drift chambers with gas mixtures, using isobutane as a quencher. The positive ions of isobutane which migrate towards the cathodes may however polymerize and form a thin insulating layer on the cathodes. This layer may be the cause of discharges (Malter effect) which considerably reduces the lifetime of the chambers [2]. In order to overcome this problem, a new quenching agent, which does not polymerize and has an ionization potential lower than that of isobutane, is added to the gas mixture. A charge-exchange process takes place during the migration of the positive ions towards the cathode (Kallmann-Rosen effect), and in this way the majority of the ions reaching the cathode originate from the added gas. Many gases and vapours can be used for this purpose ; methylal $\left(\mathrm{OCH}_{3}\right)_{2} \mathrm{CH}_{2}$, has frequently been used. It is therefore essential to ensure that the ions which reach the cathode are not ions of isobutane, and to determine the proportion of methylal required for the charge exchange between the isobutane ion and the methylal ion to take place efficiently.

ii) The positive ions produced around the anode wire during gas amplification give rise to a space charge, which reduces the electrical field locally around the wire and therefore the multiplication factor. The chamber is then unable to detect particles efficiently at high incident fluxes [3]. Obviously, a higher ion mobility will allow operation of the chambers at higher rates.

In this article we shall study the mobility of positive ions in different gas mixtures frequently used in proportional and drift chambers. These mixtures are, in succession :

- argon-isobutane

- argon-isobutane-methylal

- argon-carbon dioxide

- argon-methane.

Some conclusions regarding the nature of the ions which migrate in these mixtures can be drawn. 
2. Apparatus and measurement method. - The measurements were carried out using the special drift chamber shown in figure 1.

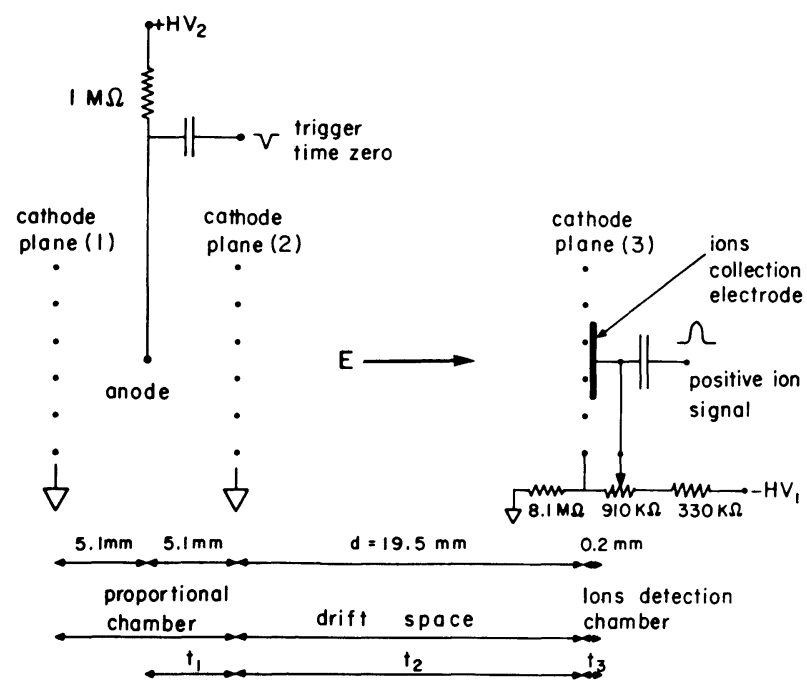

Fig. 1. - Diagram of the drift chamber used for measuring the mobility of positive ions. The chamber consists of three areas : a proportional chamber, a drift space, and a space for collecting positive charges. Only $t_{2}$ varies as a function of $E$, from which the mobility coefficient can be determined for fields of $E \leqslant 5 \mathrm{kV} / \mathrm{cm}$.

When the proportional chamber section is irradiated by an ${ }^{55} \mathrm{Fe}$ source, a negative signal on the anode provides the zero time, i. e. the time at which the positive ions start moving towards the collecting electrode located behind the drift space. The drift time of the ions consists of three times

$$
t=t_{1}+t_{2}+t_{3},
$$

corresponding respectively to the migration time from the anode to cathode 2 , to the migration time in the drift space (between the cathode planes 2 and 3),

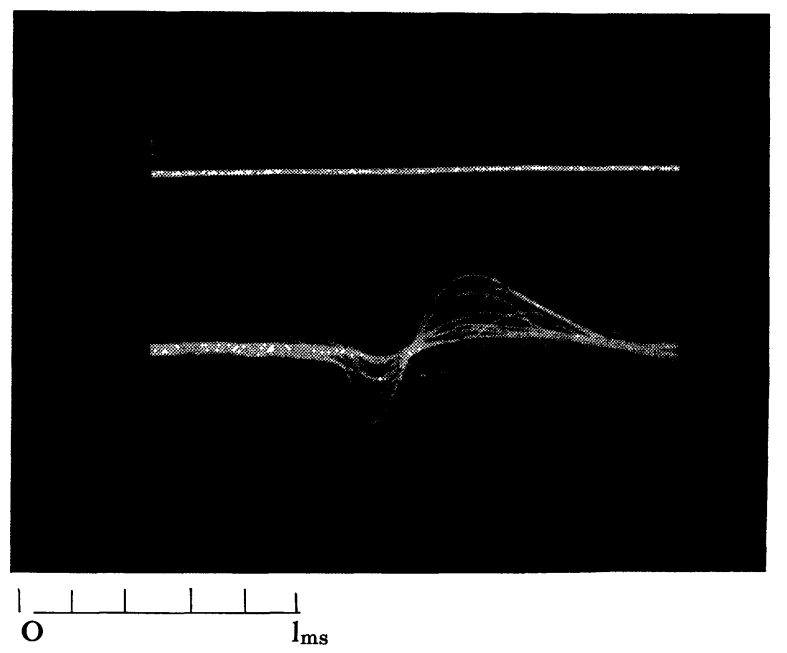

Fig. 2. - Typical electrical pulses collected on the chamber after amplification and differentiation (and inversion) : $a$ ) Anode signal : zero time ; $b$ ) Signal generated by the positive ions and picked up on the charge-collecting electrode. Horizontal scale : $200 \mu \mathrm{s} /$ square. and finally to the collection time corresponding to integration of the ion current between cathode 3 and the collecting electrode. This integration produces a positive pulse on the collecting electrode; after amplification, the position of the peak is determined by differentiation (zero-crossing). Figure 2 shows a pulse of this type.

For a given gas mixture, $-\mathbf{H V}_{\mathbf{1}}$ is varied, thus causing a change in the electrical field $E$ in the drift space, and $t$ is measured as a function of $E$. During measurement, $t_{1}$ is constant and $t_{3}$ is maintained constant by ensuring that a constant potential difference exists between cathode plane 3 and the collecting electrode.

By definition, the mobility of the migrating ions is given by

$$
\mu=\frac{d}{t_{2} E} .
$$

Since all measurements are done in a region of low field, we have assumed a constant mobility and, therefore, deduced $\mu$ from the slope of the $t_{2}$ versus $E^{-1}$ dependence.

\section{Measurements of the mobility of positive ions. -} 3.1 IDENTIFICATION OF THE MIGRATING IONS. - When measuring the mobility of ions, the main difficulty is that of identifying the migrating ion. The literature on this subject is studied with errors and corrections [4]. In fact, the only way to be sure of the nature of the migrating ion is to appeal to a mass spectrometric identification [5]. In our case, the migrating ions will be labelled $\alpha, \beta, \gamma, \ldots$. Some comments will be given in section 3.2 on the nature of $\alpha, \beta, \gamma, \ldots$.

3.2 EXPERIMENTAL RESUltS. - The mobility of ions has been studied for various gas mixtures and for different proportions of gas in the mixture at room temperature and atmospheric pressure. In order to be able to plot several curves on the same diagram, mobility (or more exactly the inverse of mobility) has been plotted as a function of the density of the gas mixture. There is naturally a simple relationship between the density of the gas mixture and the proportions of the various constituents :

$$
\rho=\sum_{k} \rho(k) f(k),
$$

where $\rho(k)$ and $f(k)$ are the density and the fraction of component $k$ in the mixture, respectively.

The results of our measurements in several gas mixtures are collected in figures 3 to 5 (points with error bars). In all figures the inverse of the mobility is given as a function of the mixture density. Figure 3 shows the mobility of ions in argon-methylal (curve A) and in several argon-isobutane-methylal mixtures (curves $\mathrm{B}$ to $\mathrm{E}$ ); the methylal concentration at each measurement is shown next to the point. Curve $F$ in figure 3 shows instead the mobility of ions in 


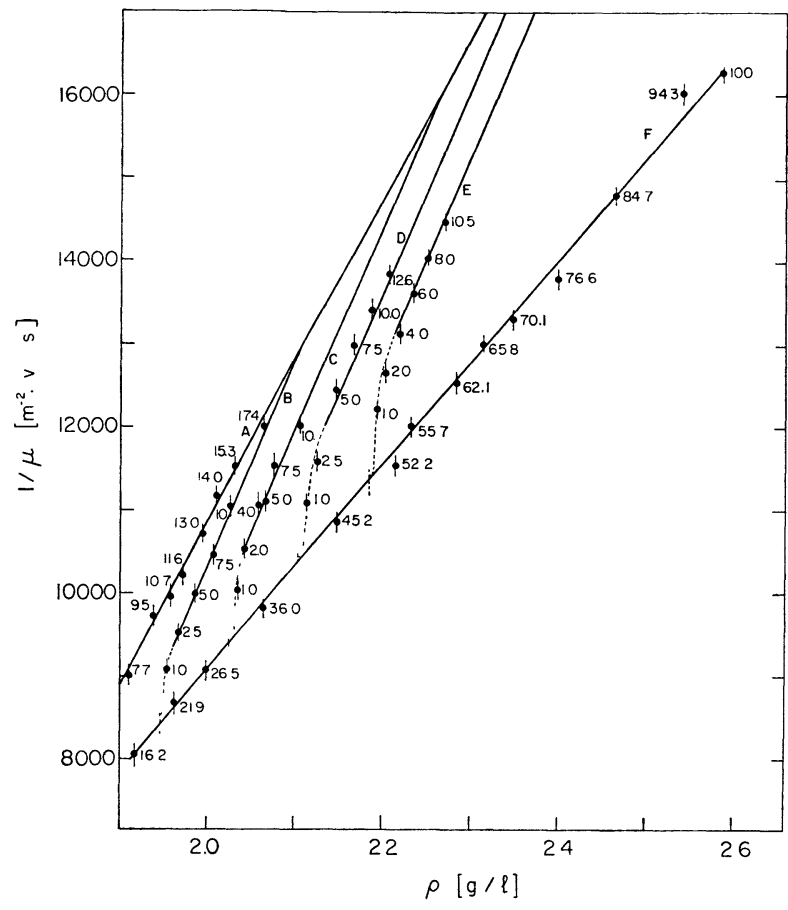

FIG. 3. - Inverse of ion mobility as a function of the density of the gas in the following gas mixtures: Curve $\mathrm{A}$ : argonmethylal ; Curve B : argon $80 \%$-isobutane-methylal ; Curve C : argon $70 \%$-isobutane-methylal ; Curve D : argon $60 \%$-isobutane-methylal ; Curve E: argon $50 \%$-isobutane-methylal. The proportion of methylal is indicated at each measurement point. The migrating ion is labelled $\alpha$ (see text). Blanc's law is fully confirmed except for low methylal contents ; Curve F : argon-isobutane. The proportion of isobutane is shown at each measurement point. The migrating ion is labelled $\beta$ (see text). Blanc's law is fully confirmed.

argon-isobutane mixtures. In this case, the isobutane concentration is shown next to each measurement.

Measurements of the mobility of ions in argonmethane mixtures are collected in figure 4 , and in argon-carbon dioxide in figure 5.

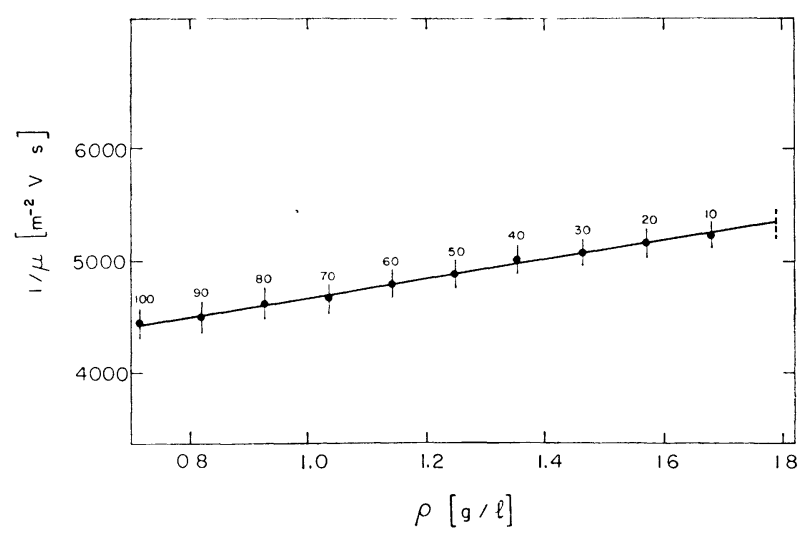

FIG. 4. - Inverse of the mobility of ions as a function of gas density in $\mathrm{Ar}-\mathrm{CH}_{4}$ gas mixtures. The migrating ion is labelled $\gamma$ (see text). The proportion of $\mathrm{CH}_{4}$ is shown at each measurement point.

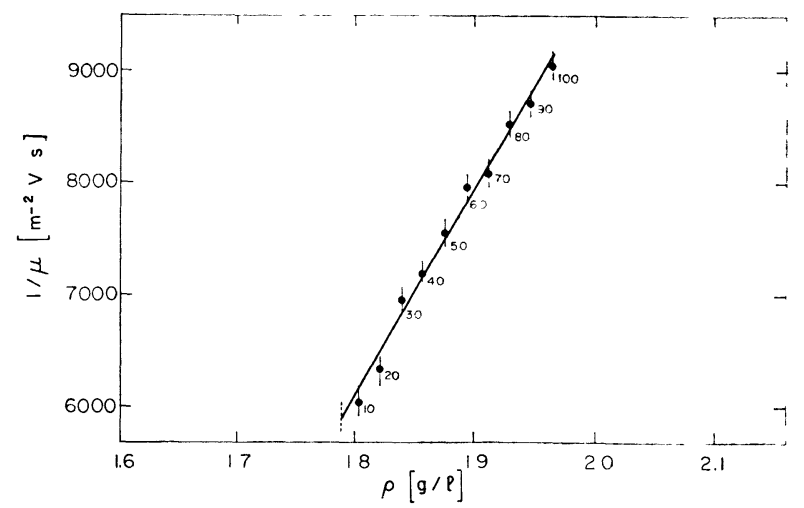

FIG. 5. - Inverse of the mobility of ions as a function of the gas density in $\mathrm{Ar}-\mathrm{CO}_{2}$ gas mixtures. The migrating ion is labelled $\delta$ (see text). The proportion of $\mathrm{CO}_{2}$ is shown at each measurement point.

In all cases we have fitted the experimental data with a curve representing Blanc's law of mobilities in gas mixtures [6] :

$$
\frac{1}{\mu\left(I^{+}, A B \ldots N\right)}=\sum_{k} \frac{f(k)}{\mu\left(I^{+}, k\right)},
$$

where $\mu\left(I^{+}, A B \ldots N\right)$ is the mobility of ion $I^{+}$in a mixture of gases $A B \ldots N$ (including $I), \mu\left(I^{+}, k\right)$ the mobility of ion $I^{+}$in gas $k$, and $f(k)$ the concentration of gas $k$ in the mixture.

It should be noticed that curves $B$ to $E$ in figure 3 meet curve $\mathrm{A}$ at concentrations of argon-methylal which are, respectively, 80-20\%, 70-30\%, 60-40\% and $50-50 \%$. We can therefore conclude that the nature of migrating ions is the same in the argonmethylal mixture as in the argon-isobutane-methylal mixture, which excludes isobutane ions. This ion is called $\alpha$. In the argon-isobutane mixture the migrating ion is called $\beta$; in argon-methane mixture it is $\gamma$; and in argon-carbon dioxide, $\delta$.

For very low methylal concentrations, the linear relationship expressed by ref. [3] is no longer followed ; this suggests that charge exchange does not take place for methylal concentration below $\simeq 3 \%$. The measured mobilities for very low concentrations tend to reach the values measured for argon-isobutane (curve F), where the $\beta$ ion is migrating. This is an important parameter to consider in view of the polymerization problems discussed in the introduction.

The mobilities $\mu\left(I^{+}, k\right)$ have been deduced from our measurements by extrapolation of the results obtained in binary mixtures to zero concentration of one component, and then used in the three-component mixtures. Table I shows the results of the fit. As an example, the mobility of $\alpha$ ions in argon-isobutane-methylal mixtures can be described by

$$
\frac{1}{\mu}=\frac{f[A]}{1.51 \times 10^{-4}}+\frac{f\left[\mathrm{IsoC}_{4} \mathrm{H}_{10}\right]}{0.55 \times 10^{-4}}+\frac{f\left[\left(\mathrm{OCH}_{3}\right)_{2} \mathrm{CH}_{2}\right]}{0.26 \times 10^{-4}}
$$

with $\mu$ given in $\mathrm{m}^{2} \mathrm{~V}^{-1} \mathrm{~s}^{-1}$. 
TABLE I

Summary of the experimental results (210-23 ${ }^{\circ} \mathrm{C}$, atmospheric pressure)

\begin{tabular}{lcc}
\multicolumn{1}{c}{ Gas } & Ions & $\begin{array}{c}\text { Mobility }\left(\mathrm{m}^{2} \mathrm{~V}^{-1} \mathrm{~s}^{-1}\right) \\
\times 10^{4}\end{array}$ \\
Argon & $\bar{\alpha}$ & $\overline{1.51}$ \\
Isobutane & $\alpha$ & 0.55 \\
Methylal & $\alpha$ & 0.26 \\
Argon & $\beta$ & 1.56 \\
Isobutane & $\beta$ & 0.61 \\
Argon & $\gamma$ & 1.87 \\
$\mathrm{CH}_{4}$ & $\gamma$ & 2.26 \\
Argon & $\delta$ & 1.72 \\
$\mathrm{CO}_{2}$ & $\delta$ & 1.09
\end{tabular}

The mobility values found for argon- $\mathrm{CO}_{2}$ mixtures are in agreement with those obtained by Saporoschenko [7], who found

$$
\mu\left(\mathrm{CO}_{2}^{+}, \mathrm{CO}_{2}\right)=1.13 \times 10^{-4} \mathrm{~m}^{2} \mathrm{~V}^{-1} \mathrm{~s}^{-1}
$$

at a temperature around $30^{\circ} \mathrm{C}$. We conclude, therefore, that there is a strong possibility that $\delta$ is $\mathrm{CO}_{2}^{+}$.

4. Conclusions. - In all the gas mixtures considered, Blanc's law of positive ion mobility has been verified, except for a very small methylal concentration in argon-isobutane-methylal. The law permits the calculation of ion mobility in any mixture of the gases considered.

The nature of the migrating ion cannot be determined with certainty by our method of measurement. Nevertheless, it is possible to conclude that the migrating ion in an argon-isobutane-methylal gas mixture is not the same as in an argon-isobutane mixture. This is an important piece of information in view of the timedegeneracy of multiwire proportional and drift chambers.

Acknowledgement. - We are indebted to Mr. Bouclier for technical help in the construction of the chambers and for the preliminary tests of the experimental set-up.

\section{References}

[1] Charpak, G., Ann. Rev. Nucl. Sci. 20 (1970) 195.

[2] Charpak, G., Fischer, G., Gruhn, G. R., Minten, A., SAULI, F., PlCh, G. and FlüGGE, G., Nucl. Instrum. Methods 99 (1972) 279.

[3] Breskin, A., Charpak, G., Sauli, F., Atkinson, M. and Schultz, G., Nucl. Instrum. Methods 124 (1975) 189.

[4] See, for instance, HoRnBeCK, J. A., Phys. Rev. 80 (1950) 297.

[5] See, for instance, Saporoschenko, M., Phys. Rev. A 139 (1965) 349.
Saporoschenko, M., J. Chem. Phys. 49 (1968) 768.

Albritton, D. L., Miller, T. M., Martin, D. W. and MCDaniel, E. W., Phys. Rev. 171 (1968) 94.

McAfee, K. B. Jr., SiPler, D. and Edelson, D., Phys. Rev. 160 (1967) 130.

[6] Blanc, A., J. Physique 7 (1908) 825.

[7] Saporoschenko, M., Phys. Rev. A 8 (1973) 1044. 